ANNOUNCEMENT

\title{
Best Paper and Best Reviewer Awards 2021
}

Published online: 22 February 2022

(c) World Maritime University 2022

\section{Best Paper Award}

Each year WMU Journal of Maritime Affairs will choose an exceptional paper on the merit of scientific contribution to the field for this award. The awardee(s) will be selected at the sole discretion of the Editor-in-Chief and will be chosen from papers published in the latest volume. JOMA would like to thank all the authors for entrusting it with their research works and appreciate their involvement in retaining JOMA's reputation as a flagship journal for professionals in the field of maritime affairs.

The Best Paper Award 2021 goes to:

\section{ANGELOS PANTOUVAKIS AND ATHINA SYNTYCHAKI}

For their paper entitled

“The Role of Shipping Companies' Organizational Culture and Cultural Intelligence When Selecting Manning Agencies (Vol. 20, No. 3, pp. 279-308)"

\section{Best Reviewer Award}

The WMU Journal of Maritime Affairs would like to thank all reviewers for their effort, time and expertise made themselves available for the journal. Without the commitment of the reviewers as a gate keeper for the quality, it would be impossible to maintain JOMA's high quality standard. This award will be presented to one(s) who made a substantial contribution with an effort devoted in a professional and voluntary manner. The selection is made at the sole discretion of the Editorin-Chief and will be chosen from those staunch reviewers worked for the latest volume.

The Best Reviewer Award 2021 goes to:

\section{STAVROS KARAMPERIDIS}

University of Plymouth

More information on the awards is available on the journal website.

Publisher's Note Springer Nature remains neutral with regard to jurisdictional claims in published maps and institutional affiliations. 